\title{
What is the incidence of cauda equina syndrome? A systematic review
}

\author{
*Ingrid Hoeritzauer, MRCP, ${ }^{2,3}$ Matthew Wood, BSc, $, 1,2$ Phillip C. Copley, MRCS,1-3 \\ Andreas K. Demetriades, FRCSEd, ${ }^{1,3}$ and Julie Woodfield, MSc ${ }^{1,2}$
}

\begin{abstract}
'Department of Clinical Neurosciences, Western General Hospital, Edinburgh; ${ }^{2}$ Centre for Clinical Brain Sciences, University of Edinburgh; and ${ }^{3}$ Edinburgh Spinal Surgery Outcome Studies Group, Department of Clinical Neurosciences, Edinburgh, United Kingdom
\end{abstract}

\begin{abstract}
OBJECTIVE Cauda equina syndrome (CES) is a surgical emergency requiring timely operative intervention to prevent symptom progression. Accurately establishing the incidence of CES is required to inform healthcare service design and delivery, including out-of-hours imaging arrangements.
\end{abstract}

METHODS A systematic literature search of MEDLINE, EMBASE, and Scopus was undertaken to identify original studies stating the incidence of CES, and the estimates were combined in a meta-analysis as described in the protocol registered with PROSPERO (registration no. CRD42017065865) and reported using the PRISMA guidelines.

\begin{abstract}
RESULTS A total of 1281 studies were identified, and 26 studies were included in the review. Data about CES incidence were available from 3 different populations: asymptomatic community populations, patients with nontraumatic low-back pain, and patients presenting as an emergency with suspected CES. The incidence of CES was $0.3-0.5$ per 100,000 per year in 2 asymptomatic community populations, 0.6 per 100,000 per year in an asymptomatic adult population, and 7 per 100,000 per year in an asymptomatic working-age population. CES occurred in $0.08 \%$ of those with low-back pain presenting to primary care in 1 study, and a combined estimate of $0.27 \%$ was calculated for 4 studies of those with low-back pain presenting to secondary care. Across 18 studies of adults with suspected CES, $19 \%$ had radiological and clinical CES. Difficulties in comparison between studies resulted from the heterogeneous definitions of CES and lack of separation of more advanced CES with retention, which is unlikely to be reversible. In the studies of patients with suspected CES, the small sample size, the high number of single-center studies (18/18), the high number of studies from the United Kingdom (17/18), the retrospective nature of the studies, and the high number of abstracts rather than full texts $(9 / 18)$ reduced the quality of the data.
\end{abstract}

CONCLUSIONS From current studies, it appears that CES occurs infrequently in asymptomatic community populations and in only $19 \%$ of those presenting with symptoms. Determining accurate incidence figures and designing a bespoke service for investigation of patients with suspected CES would require a consensus clinical and radiological definition of CES and international multisite studies of patient pathways of investigation and management.

https://thejns.org/doi/abs/10.3171/2019.12.SPINE19839

KEYWORDS cauda equina syndrome; incidence; systematic review; epidemiology; population; lumbar

$\mathrm{C}$ AUDA equina syndrome (CES) is a surgical emergency with potentially significant consequences, including bladder, bowel and sexual dysfunction, numbness, weakness, and pain. ${ }^{18,31}$ Timely operative intervention can prevent symptom progression and potentially reverse existing symptoms..$^{2,9,46}$ Due to the high medical, personal, social, and legal costs, prompt investigation with MRI is recommended when CES is suspected. ${ }^{19,49}$ In the United Kingdom (UK), patients are often transferred for investigation between sites due to a lack of MRI facilities operating outside normal working hours in district general hospitals and the potential need for specialist spinal or neurosurgical intervention..$^{11,29}$ However, many patients who present with clinical symptoms in keeping with CES will not have cauda equina compression on MRI ${ }^{26}$ which complicates planning service design and delivery. Establishing the incidence of CES and the likelihood of a diagnosis of CES in those presenting with symptoms consistent with CES would facilitate planning imaging and operative pathways for patients with suspected CES.

ABBREVIATIONS CES = cauda equina syndrome; UK = United Kingdom.

SUBMITTED August 14, 2019. ACCEPTED December 6, 2019.

INCLUDE WHEN CITING Published online February 14, 2020; DOI: 10.3171/2019.12.SPINE19839.

${ }^{*}$ A.K.D. and J.W. share senior authorship of this work. 
In this systematic review, we aimed to identify studies reporting the incidence of CES and describe the populations in which the incidence of CES has been studied and any differences in incidence between these populations.

\section{Methods}

A systematic review was undertaken as described in the study protocol "Incidence of cauda equina syndrome: systematic review protocol" registered with the International Prospective Register of Systematic Reviews (PROSPERO; reference no. CRD42017065865, available at https://www. crd.york.ac.uk/PROSPERO/display_record.php?Record $\mathrm{ID}=65865$ ).

Studies were included if they reported original data and assessed human subjects with CES. For inclusion, studies had to state the incidence of CES or the proportion of the studied population with CES, or provide sufficient figures for this to be calculated. We defined CES as a clinical diagnosis of CES with radiological cauda equina compression. Studies including only patients with a clinical CES-type syndrome without radiologically confirmed cauda equina compression were excluded. Studies of radiological lesions of the cauda equina or cauda equina compression without clinical features of CES were also excluded. Reference populations could be either asymptomatic or symptomatic populations. Case series or studies without a reference population where the incidence of CES could not be established were excluded. Case series of operated lumbar discs, spinal stenosis, or iatrogenically caused CES were also excluded to ensure that all included studies were applicable to an initial presentation with suspected CES. There were no restrictions on the language or year of publication; type, location, or age of the population studied; or whether the study was published or unpublished.

The final database search was carried out on July 30 , 2018, in MEDLINE (Epub Ahead of Print, In-Process \& Other Non-Indexed Citations, and Daily 1946 to July 27, 2018, Ovid interface); EMBASE (1980 to week 31 of 2018, Ovid interface); and Scopus. The MEDLINE search strategy was as follows:

1) Polyradiculopathy/

2) cauda equina.ti,ab.

3) Cauda Equina/

4) 1 OR 2 OR 3

5) Incidence/ or Prevalence/

6) Epidemiology/

7) (incidence* or prevalen* or epidemiolog* or frequenc* or rate* or occurrence*).ti,ab

8) 5 OR 6 OR 7

9) 4 AND 8

No limits were applied. EMBASE and Scopus search strategies are given in the Appendix.

Duplicate studies were eliminated, and then all abstracts and titles were screened by 2 reviewers independently (J.W., I.H., P.C.C., or M.W.). When reviewers disagreed, discussion with a third or fourth reviewer was undertaken to provide a consensus. The full text of all included abstracts was retrieved and independently reviewed by 2 reviewers (J.W., I.H., P.C.C., or M.W.). Any disagreements were resolved through discussion with a third or fourth reviewer. The reference lists of all included studies were screened independently by 2 reviewers to identify any additional relevant papers. Studies citing the included studies were identified using Scopus and also screened by 2 reviewers independently. Multiple papers or abstracts reporting the same study were treated as a single study.

Data were extracted from each included paper by 2 reviewers independently, and all instances in which data did not match were checked by a third reviewer (J.W., I.H., P.C.C., or M.W.). The data items extracted were incidence of CES in the population (including confidence intervals and standardized estimates where given); number of cases of CES; size of the reference population; description of the population (location, demographics, time period studied, inclusion criteria); and definition of CES used in the study including any subcategorization.

Study quality and risk of bias were assessed using the following questions adapted from those used in prior systematic reviews of the incidence of neurological conditions $s^{16,35}$ based on published quality assessment guidelines. ${ }^{8,33}$ As there are no validated diagnostic criteria for CES, studies were assessed on whether they described the definition of CES used.

1) Was the target population clearly described?

2) Were cases ascertained by survey of the entire population or by probability sampling?

3) Was the sample size $>300$ subjects?

4) Was the response rate $>70 \%$ ?

5) Were nonresponders clearly described?

6) Was the sample representative of the population?

7) Were data collection methods standardized?

8) Were the diagnostic criteria used to assess the presence of disease described?

9) Were estimates of incidence given with confidence intervals?

10) Were standardized estimates reported?

The incidence of CES was reported per 100,000 population per year in asymptomatic populations. The percentage with CES was reported in symptomatic populations. Statistical heterogeneity was assessed using the Q statistic and the $\mathrm{I}^{2}$ test. ${ }^{24}$ Proportions were combined using the inverse variance method and a DerSimonian-Laird estimator for $\tau^{2}{ }^{14}$ Confidence intervals for individual studies were calculated using Clopper-Pearson confidence intervals. ${ }^{10}$ All statistics were calculated using the meta package in $\mathrm{R}$ version 3.4.0.4

\section{Results}

The studies identified and excluded at each stage and reasons for exclusion are shown in the PRISMA flow diagram (Fig. 1). ${ }^{36}$ Of the 1281 studies identified after removal of duplicates, 26 were included, of which 21 were included in the meta-analysis. Four studies reported the incidence of CES occurring in asymptomatic community populations..$^{28,37,40,43}$ Twenty-three studies investigated the incidence of CES in patients presenting with symptoms. . $^{1,3-7}$, $11,13,15,20,22,23,25,27,29,30,32,38,40,41,45,47,48$ One study was included in both of these categories. ${ }^{40}$ 


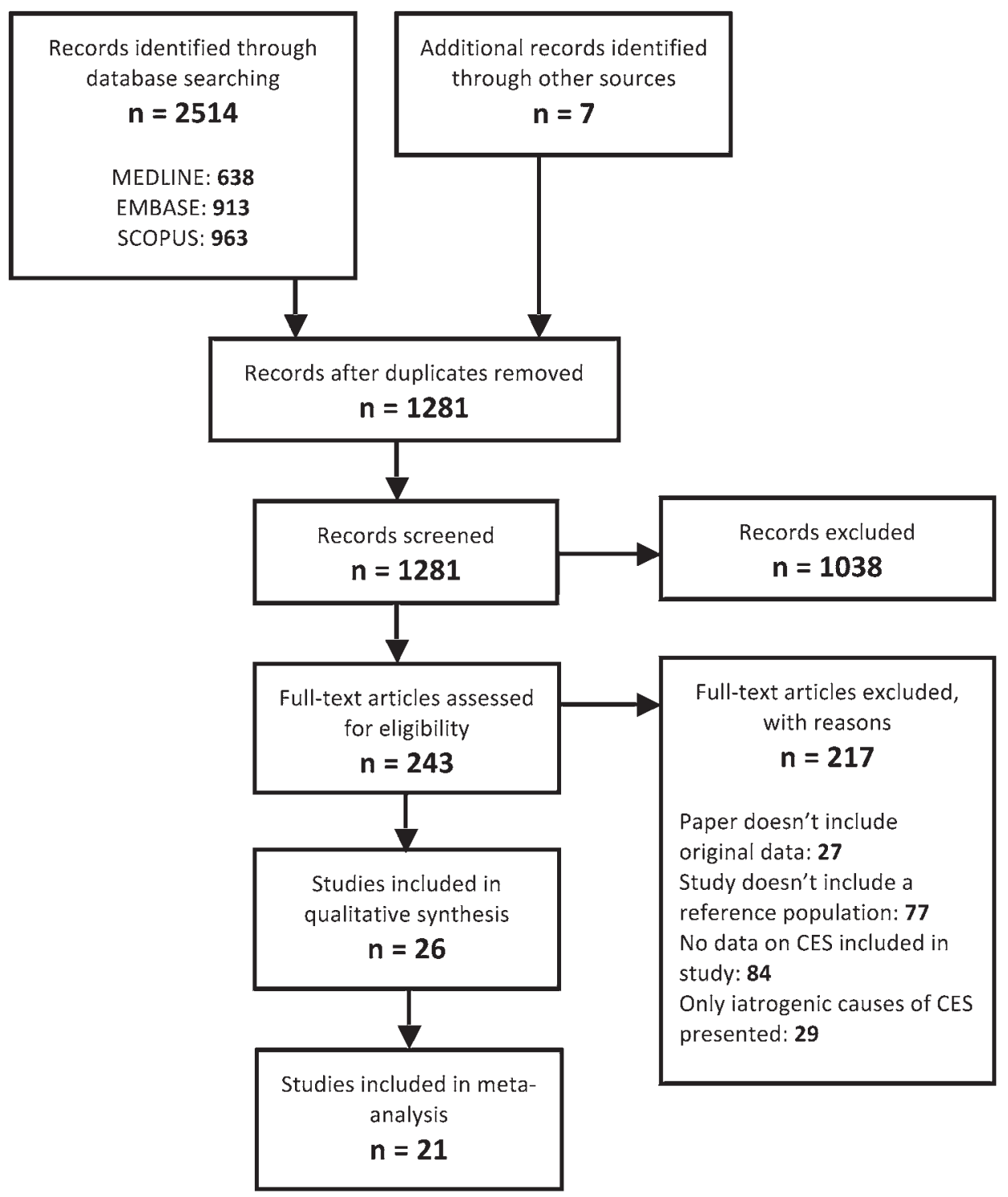

FIG. 1. PRISMA flow diagram. Studies identified, included, and excluded.

\section{Population Incidence of CES}

Study details and incidence figures for the 4 studies reporting the incidence of CES in community-dwelling asymptomatic populations are shown in Table 1. Hurme et al. ${ }^{28}$ and Podnar $^{37}$ investigated European communitydwelling populations and identified similar incidence figures of 0.48 and 0.34 cases per 100,000 population per year, respectively, despite different methods of case ascertainment. Hurme et al. ${ }^{28}$ identified cases of CES using surgical records, while Podnar ${ }^{37}$ used a comprehensive clinical and neurophysiological assessment at a rehabilitation center. Reito et al. ${ }^{40}$ reported the incidence in an adult-only population and found a slightly higher incidence of 0.6 per 100,000 adult population per year. Schoenfeld ${ }^{42}$ and Schoenfeld and Bader ${ }^{43}$ studied an American military personnel healthcare database and found a higher incidence of 7 per 100,000 population per year in this working-age population. The study by Reito et al..$^{40}$ was the only one to divide CES into subcategories. Two patients had CES with retention and 2 patients had incomplete CES, making the incidence of each subtype 0.30 per 100,000 per adult population per year. Both Reito et al. and Schoenfeld and Bader ${ }^{43}$ used coding to identify cases of CES. Reito et al. also reviewed clinical notes of the identified cases. Meta-analysis of the incidence estimates was not undertaken due to the heterogeneity in the reference populations studied and the methods of CES case ascertainment.

\section{Incidence of CES in Patients With Back Pain}

Five studies reported the proportion of patients presenting with nontraumatic low-back pain who were found to have CES..$^{23,30,38,40,48}$ Study findings are shown in Table 2 . Henschke et al. ${ }^{23}$ found that $0.08 \%$ of adults presenting to primary care in Australia with low-back pain were 
TABLE 1. Incidence of CES in asymptomatic community populations

\begin{tabular}{|c|c|c|c|c|c|c|c|}
\hline $\begin{array}{l}\text { Authors \& } \\
\text { Study }\end{array}$ & $\begin{array}{l}\text { Yrs of } \\
\text { Study }\end{array}$ & $\begin{array}{l}\text { Time } \\
\text { Period }\end{array}$ & Reference Population & Definition of CES & $\begin{array}{c}\text { Total } \\
\text { Population }\end{array}$ & $\begin{array}{l}\text { Total } \\
\text { Cases }\end{array}$ & $\begin{array}{l}\text { Cases } / 100,000 / \mathrm{Yr} \\
(95 \% \mathrm{Cl})\end{array}$ \\
\hline $\begin{array}{l}\text { Hurme et al., } \\
1983\end{array}$ & 1975-1979 & $5 \mathrm{yrs}$ & $\begin{array}{l}\text { Hospital catchment } \\
\text { population, Finland }\end{array}$ & Undergoing operation for CES & 455,000 & 11 & $0.48^{*}$ \\
\hline Podnar, 2007 & $1996-2004$ & $8 \mathrm{yrs}$ & $\begin{array}{l}\text { Population of Slo- } \\
\text { venia }\end{array}$ & $\begin{array}{l}\text { History, examination, neurophysiol- } \\
\text { ogy \& radiology }\end{array}$ & $1,989,198$ & 67 & 0.34 \\
\hline $\begin{array}{l}\text { Schoenfeld \& } \\
\text { Bader, } 2012\end{array}$ & $2001-2010$ & $9 \mathrm{yrs}$ & $\begin{array}{l}\text { American military } \\
\text { database, US }\end{array}$ & ICD code & $\begin{array}{c}13,871,384 \\
\text { person-yrs } †\end{array}$ & 976 & 7 \\
\hline $\begin{array}{l}\text { Reito et al., } \\
2018\end{array}$ & 2012-2014 & 3 yrs & $\begin{array}{l}\text { Hospital catchment } \\
\text { population, Finland }\end{array}$ & $\begin{array}{l}\text { ICD code; SBNS guideline subcat- } \\
\text { egories based on clinical records }\end{array}$ & $\begin{array}{l}661,902 \text { adult } \\
\text { person-yrs } \dagger\end{array}$ & 4 & $0.6(0.16-1.5)$ \\
\hline
\end{tabular}

SBNS $=$ Society of British Neurological Surgeons

* Calculated from values given in paper.

$\dagger$ Reported as the total number of people in the population in the total number of years during the study time period.

diagnosed with CES by the study rheumatologist using clinical assessment and investigation. The other 4 studies investigated patients presenting to secondary care and reported proportions between $0.15 \%$ and $0.54 \% .30,38,40,48$ The diagnosis of CES was determined by ICD code in 2 studies $^{38,40}$ and by the clinician in 1 study; ${ }^{48}$ the method was not reported in 1 study. ${ }^{30}$ Study estimates for the proportion with CES in those presenting to secondary care with nontraumatic low-back pain were combined using a random-effects model to give an estimated proportion of $0.27 \%$ (95\% CI $0.14 \%-0.54 \%$ ). Study estimates and confidence intervals are shown in the forest plot in Fig. 2. There was a high level of statistical heterogeneity, with $\mathrm{I}^{2}$ $=85.2 \%(95 \%$ CI 63.3\%-94.0\%) and $\mathrm{Q}=20.2(\mathrm{p}<0.001)$.

\section{Incidence of Confirmed CES in Patients Suspected of Having CES}

Eighteen studies reported the proportion of patients presenting with signs and symptoms suspicious for CES who had clinical and radiological confirmation of CES. The study details are shown in Table 3. Ten studies included only patients undergoing MRI for suspected CES. ${ }^{3,6,11 \text {, }}$ 13,15,20,22,25,32,41,47 Two studies included patients undergoing urgent spinal MRI, but did not specify whether this was to investigate CES in every case. ${ }^{1,47}$ Six studies included all patients referred with suspected CES.,4,7,27,29,39,45 All studies assessed populations referred to either secondary or tertiary care. Banerjee and Jalgaonkar ${ }^{5}$ studied only children. All other studies included adult populations but did not state whether they specifically excluded pediatric patients. A diagnosis of CES was established by cauda equina compression on MRI or operative intervention for CES. The imaging type in all studies was MRI. Only 2 studies described findings on MRI defining a diagnosis of CES based on the finding of canal compromise, which was more than $50 \%$ in one study ${ }^{29}$ and more than $75 \%$ in the other. ${ }^{26}$ Three studies stated that cauda equina compression was determined by the reporting radiologist but did not state the criteria used..$^{15,20,32}$ The cause of cauda equina compression was described in 6 studies. Demetriades et al. ${ }^{13}$ only included disc prolapses. Five studies included all or some of disc prolapses, tumors, trauma, and hematoma. $1,7,11,15,20$ One study discussed subtypes of CES (with urinary symptoms or incomplete CES) but did not report the numbers in each group. None of the other studies used subcategories or descriptors. Four studies provided information on symptom duration. Urinary symptoms in 2 studies were present for an average of 4 and 5.8 days, and symptoms not further specified were present for between 24 hours and 6 months and a median

TABLE 2. Incidence of CES in patients presenting with back pain

\begin{tabular}{|c|c|c|c|c|c|c|c|}
\hline Authors \& Study & $\begin{array}{l}\text { Yrs of } \\
\text { Study }\end{array}$ & $\begin{array}{l}\text { Time } \\
\text { Period }\end{array}$ & $\begin{array}{l}\text { Reference } \\
\text { Population }\end{array}$ & Definition of CES & $\begin{array}{c}\text { Total } \\
\text { Population }\end{array}$ & $\begin{array}{l}\text { Total } \\
\text { Cases }\end{array}$ & $\begin{array}{c}\text { Proportion w/ CES } \\
(95 \% \mathrm{Cl})\end{array}$ \\
\hline Henschke et al., 2009 & 2003-2005 & 20 mos & $\begin{array}{c}\text { Primary care, } \\
\text { Australia }\end{array}$ & $\begin{array}{l}\text { Rheumatologist assessment } \\
\text { (history, exam, tests) }\end{array}$ & 1172 & 1 & $0.08 \%(0.0-0.5 \%)$ \\
\hline $\begin{array}{l}\text { Thiruganasambandamoorthy } \\
\text { et al., } 2014\end{array}$ & $2009-2010$ & 3 mos & Adults, ED, Canada & Clinician determined & 329 & 1 & $0.30 \%$ \\
\hline Kiberd et al., 2018 & Not stated & $7 \mathrm{yrs}$ & ED, Canada & Not stated & 38,714 & 57 & $0.15 \%$ \\
\hline Premkumar et al., 2018 & $2005-2016$ & $11 \mathrm{yrs}$ & Spinal surgeon, US & ICD code & 9940 & 36 & $0.36 \%$ \\
\hline Reito et al., 2018 & $2012-2014$ & 3 yrs & Adults, ED, Finland & $\begin{array}{l}\text { ICD code; SBNS guideline } \\
\text { subcategories - based on } \\
\text { clinical records }\end{array}$ & $\begin{array}{l}900 \text { visits; } \\
737 \text { patients }\end{array}$ & 4 & $\begin{array}{l}0.44 \% \text { per visit; } \\
0.54 \% \text { per patient }\end{array}$ \\
\hline
\end{tabular}

$E D=$ emergency department. 
Study

Thiruganasambandamoorthy 2014

Kiberd 2018

Premkumar 2018

Reito 2018

Random effects model

Heterogeneity: $I^{2}=85 \%, \tau^{2}=0.3359$
Events Total

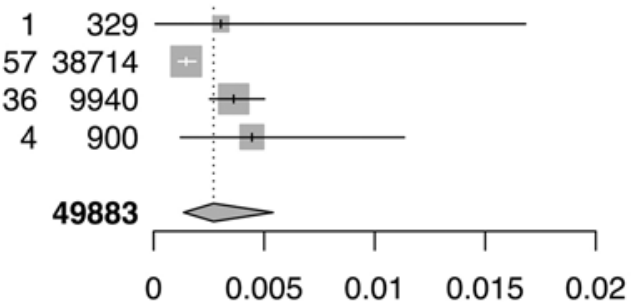

Proportion

95\%-Cl Weight

$0.0030[0.0001 ; 0.0168] \quad 9.3 \%$

$0.0015[0.0011 ; 0.0019] \quad 35.2 \%$

$0.0036[0.0025 ; 0.0050] 34.2 \%$

$0.0044[0.0012 ; 0.0113] 21.2 \%$

$0.0027[0.0014 ; 0.0054] 100.0 \%$

FIG. 2. Forest plot. Proportion and number (events) of patients with CES among those presenting with nontraumatic low-back pain to secondary care. Summary proportion calculated using a random effects model.

TABLE 3. Incidence of CES in patients presenting with suspected CES

\begin{tabular}{|c|c|c|c|c|c|c|c|c|}
\hline Authors \& Study & $\begin{array}{l}\text { Yrs of } \\
\text { Study }\end{array}$ & $\begin{array}{l}\text { Time } \\
\text { Period }\end{array}$ & $\begin{array}{l}\text { Reference Population: Potential } \\
\text { CES }\end{array}$ & Definition of CES & $\begin{array}{l}\text { Imaging } \\
\text { Type }\end{array}$ & $\begin{array}{c}\text { Total } \\
\text { Population }\end{array}$ & $\begin{array}{l}\text { Total } \\
\text { Cases }\end{array}$ & $\begin{array}{l}\text { Proportion } \\
\text { w/ CES }\end{array}$ \\
\hline Bell et al., 2007 & Not stated & 4 mos & MRI for ?CES, neurosurgery, UK & MRI CE compression & MRI & 23 & 5 & $21.7 \%$ \\
\hline $\begin{array}{l}\text { Crocker et al., } \\
2008\end{array}$ & Not stated & $2 \mathrm{yrs}$ & $\begin{array}{l}\text { OOH MRI for ?CES, neurosur- } \\
\text { gery, UK }\end{array}$ & Surgery for CES & MRI & 82 & 27 & $32.9 \%$ \\
\hline $\begin{array}{l}\text { Demetriades et al., } \\
2009\end{array}$ & 2008 & $1 \mathrm{yr}$ & $\begin{array}{l}\text { OOH MRI for ?CES, neurosur- } \\
\text { gery, UK }\end{array}$ & $\begin{array}{l}\text { Disc on MRI \& surgery } \\
\quad \text { for CES }\end{array}$ & MRI & 33 & 10 & $30.3 \%$ \\
\hline Domen et al., 2009 & 2003-2007 & $5 \mathrm{yrs}$ & $\begin{array}{l}\text { Urgent MRI for ?CES neurology/ } \\
\text { ED, the Netherlands }\end{array}$ & $\begin{array}{l}\text { Radiology report MRI CE } \\
\text { compression }\end{array}$ & MRI & 58 & 8 & $13.8 \%$ \\
\hline $\begin{array}{l}\text { Rooney et al., } \\
2009\end{array}$ & 2004 & $10 \mathrm{mos}$ & MRI for ?CES, neurosurgery, UK & Surgery for CES & MRI & 66 & 16 & $24.2 \%$ \\
\hline $\begin{array}{l}\text { Balasubramanian } \\
\text { et al., } 2010\end{array}$ & 2008 & $1 \mathrm{yr}$ & $\begin{array}{l}\text { MRI for ?CES, spinal surgery, } \\
\text { UK }\end{array}$ & $\begin{array}{l}\text { Radiology report }>75 \% \\
\text { canal compromise }\end{array}$ & MRI & 80 & 15 & $18.8 \%$ \\
\hline $\begin{array}{l}\text { Thangarajah et al., } \\
2011\end{array}$ & $2006-2007$ & $1 \mathrm{yr}$ & $\begin{array}{l}\text { Urgent spinal MRI, teaching } \\
\text { hospital, UK }\end{array}$ & Not stated & MRI & 81 & 0 & $0 \%$ \\
\hline $\begin{array}{l}\text { Gooding et al., } \\
2013\end{array}$ & 2008 & $1 \mathrm{yr}$ & $\begin{array}{l}\text { MRI for ?CES, hospital w/ spinal } \\
\text { unit, UK }\end{array}$ & $\begin{array}{l}\text { Radiology report CE } \\
\text { compression }\end{array}$ & MRI & 57 & 13 & $22.8 \%$ \\
\hline $\begin{array}{l}\text { Haworth et al., } \\
2013\end{array}$ & $2009-2011$ & 3 yrs & $\begin{array}{l}\text { OOH MRI for ?CES, neurosur- } \\
\text { gery, UK }\end{array}$ & MRI CE compression & MRI & 162 & 39 & $24.1 \%$ \\
\hline Sideris et al., 2014 & 2010-2013 & 4 yrs & ?CES, neurosurgery, UK & $\begin{array}{l}\text { Clinical \& radiological } \\
\text { CES }\end{array}$ & MRI & 663 & $80^{*}$ & $12.0 \%$ \\
\hline Ahad et al., 2015 & 2012-2013 & $8 \mathrm{mos}$ & Urgent spinal MRI, hospital, UK & MRI CE compression & MRI & 79 & 5 & $6.3 \%$ \\
\hline Blades et al., 2015 & 2008-2014 & $7 \mathrm{yrs}$ & ?CES, spinal unit, UK & MRI CE compression & MRI & 344 & 137 & $40 \%$ \\
\hline $\begin{array}{l}\text { Hoeritzauer et al., } \\
2015\end{array}$ & 2013-2014 & $6 \mathrm{mos}$ & $\begin{array}{l}\text { Urgent MRI for ?CES spinal } \\
\quad \text { unit, UK }\end{array}$ & MRI CE compression & MRI & 18 & 7 & $38.9 \%$ \\
\hline $\begin{array}{l}\text { Hoeritzauer et al., } \\
2017\end{array}$ & 2013-2014 & $16 \mathrm{mos}$ & ?CES, neurosurgery, UK & MRI CE compression & MRI & 290 & 91 & $31.4 \%$ \\
\hline $\begin{array}{l}\text { Kostusiak et al., } \\
2018\end{array}$ & 2014-2017 & $4 \mathrm{yrs}$ & $\begin{array}{l}\text { OOH MRI for ?CES, neurosur- } \\
\text { gery, UK }\end{array}$ & $\begin{array}{l}\text { Radiology report CE } \\
\text { compression }\end{array}$ & MRI & 323 & 15 & $4.6 \%$ \\
\hline $\begin{array}{l}\text { Hussain et al., } \\
2018\end{array}$ & 2013-2014 & 14 mos & ?CES, neurosurgery, UK & $\begin{array}{l}>50 \% \text { canal compromise } \\
\text { on MRI }\end{array}$ & MRI & 250 & 32 & $12.8 \%$ \\
\hline Banerjee, 2018 & 2014-2016 & 3 yrs & ?CES, district hospital, UK & MRI CE compression & MRI & 43 & 7 & $16.3 \%$ \\
\hline $\begin{array}{l}\text { Banerjee \& } \\
\text { Jalgaonkar, } 2018\end{array}$ & $2012-2017$ & 5 yrs & $\begin{array}{l}\text { Children (0-15 yrs), ?CES, } \\
\text { district hospital, UK }\end{array}$ & MRI CE compression & MRI & 15 & 0 & $0 \%$ \\
\hline
\end{tabular}

?CES = potential $\mathrm{CES} ; \mathrm{CE}=$ cauda equina; $\mathrm{OOH}=$ out of hours.

${ }^{*}$ Calculated from paper. 
Study

Bell 2007
Crocker 2008
Demetriades 2009
Domen 2009
Rooney 2009
Balasubramanian 2010
Thangarajah 2011
Gooding 2013
Haworth 2013
Sideris 2014
Ahad 2015
Blades 2015
Hoeritzaeur 2015
Hoeritzauer 2017
Kostusiak 2018
Hussain 2018
Banerjee $2018^{4}$

Random effects model

Heterogeneity: $I^{2}=92 \%, \tau^{2}=0.5614$
Events Total

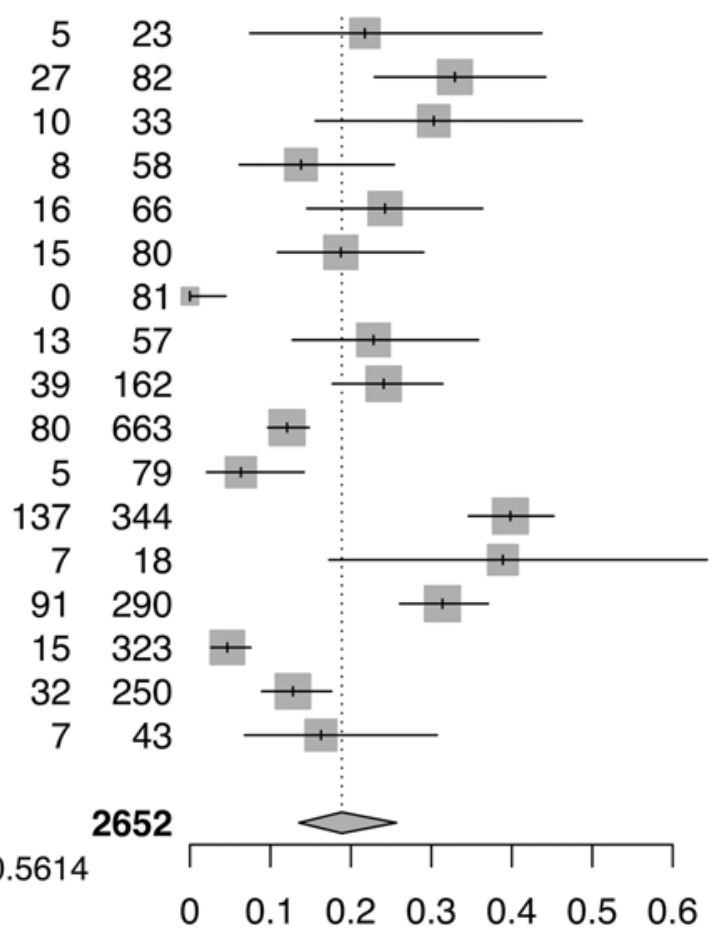

Proportion 95\%-Cl Weight

$\begin{array}{ll}0.22[0.07 ; 0.44] & 4.9 \% \\ 0.33[0.23 ; 0.44] & 6.6 \% \\ 0.30[0.16 ; 0.49] & 5.7 \% \\ 0.14[0.06 ; 0.25] & 5.7 \% \\ 0.24[0.15 ; 0.36] & 6.3 \% \\ 0.19[0.11 ; 0.29] & 6.3 \% \\ 0.00[0.00 ; 0.04] & 1.6 \% \\ 0.23[0.13 ; 0.36] & 6.1 \% \\ 0.24[0.18 ; 0.31] & 6.8 \% \\ 0.12[0.10 ; 0.15] & 7.0 \% \\ 0.06[0.02 ; 0.14] & 5.2 \% \\ 0.40[0.35 ; 0.45] & 7.0 \% \\ 0.39[0.17 ; 0.64] & 5.1 \% \\ 0.31[0.26 ; 0.37] & 7.0 \% \\ 0.05[0.03 ; 0.08] & 6.4 \% \\ 0.13[0.09 ; 0.18] & 6.8 \% \\ 0.16[0.07 ; 0.31] & 5.5 \% \\ 0.19[0.14 ; 0.26] 100.0 \%\end{array}$

FIG. 3. Forest plot. Proportion and number (events) of patients with confirmed CES among those referred to secondary or tertiary care facilities for assessment for possible CES. Summary proportion calculated using a random effects model.

of 11 days in 2 other papers. Two studies containing small numbers of patients with CES investigated whether any symptoms or signs were predictive of CES. In the 6 patients assessed with bladder scanning, Domen et al. found that urinary retention of $>500 \mathrm{ml}$ plus at least 2 of bilateral sciatica, subjective urinary retention, or rectal incontinence had an odds ratio of 48 for predicting cauda equina compression on MRI. ${ }^{15}$ In 5 patients with CES, Ahad et al. did not find any predictive symptoms but found that patients with abnormal MRI findings of the spine for back pain prior to CES presentation were significantly more likely to have radiological compression. ${ }^{1}$ These results are limited in their generalizability by the small numbers of patients involved. The proportion with confirmed CES in those presenting with suspected CES ranged from $0 \%$ to $40 \%$ in the 18 studies. We excluded the study that included only children ${ }^{5}$ and combined the other estimates using a random-effects model to give an overall estimate of confirmed CES in $18.9 \%$ (95\% CI $13.6 \%-25.6 \%$ ). The forest plot is shown in Fig. 3. There was a high level of heterogeneity in the study designs and the statistical heterogeneity was high, with $\mathrm{I}^{2}=91.9 \%$ (95\% CI 88.6\%-94.3\%) and Q $=197(\mathrm{p}<0.001)$.

\section{Study Quality}

Study quality assessment is shown in Table 4. All studies described the population being studied and had representative samples. However, definitions of CES and meth- ods used to ascertain the diagnosis of CES varied between studies, and many studies did not adequately describe their methods in a way that could be easily reproduced. Only 2 studies reported excluded patients, ${ }^{40,41}$ and only 1 study described the excluded patients..$^{40}$ Only 2 studies calculated confidence intervals for the incidence estimates, ${ }^{23,40}$ and none reported population-standardized estimates. Of the 26 studies included in this review, 9 were published only in abstract form. $4,5,7,13,22,27,30,32,45$

Studies of patients with suspected CES were of particularly poor quality. They were limited by small sample sizes; only $3(17 \%)$ studies included more than 300 participants, ${ }^{7,32,45}$ by their retrospective $(100 \%)$ and single-center design $(100 \%)$, and by the limited information available, as so many (50\%) were published only as an abstract. Of the 18 studies of patients with suspected CES, all but one were from the UK.

\section{Discussion}

This is the first systematic review of studies estimating the incidence of CES; 26 studies were included. The incidence of CES is low, at fewer than 1 per 100,000 people in asymptomatic populations per year. Only $0.27 \%$ of those with low-back pain and only $18.9 \%$ of those with signs and symptoms consistent with CES will have a final diagnosis of radiological and clinical CES.

This review identified a paucity of literature on the incidence of CES. We included all studies from which inci- 


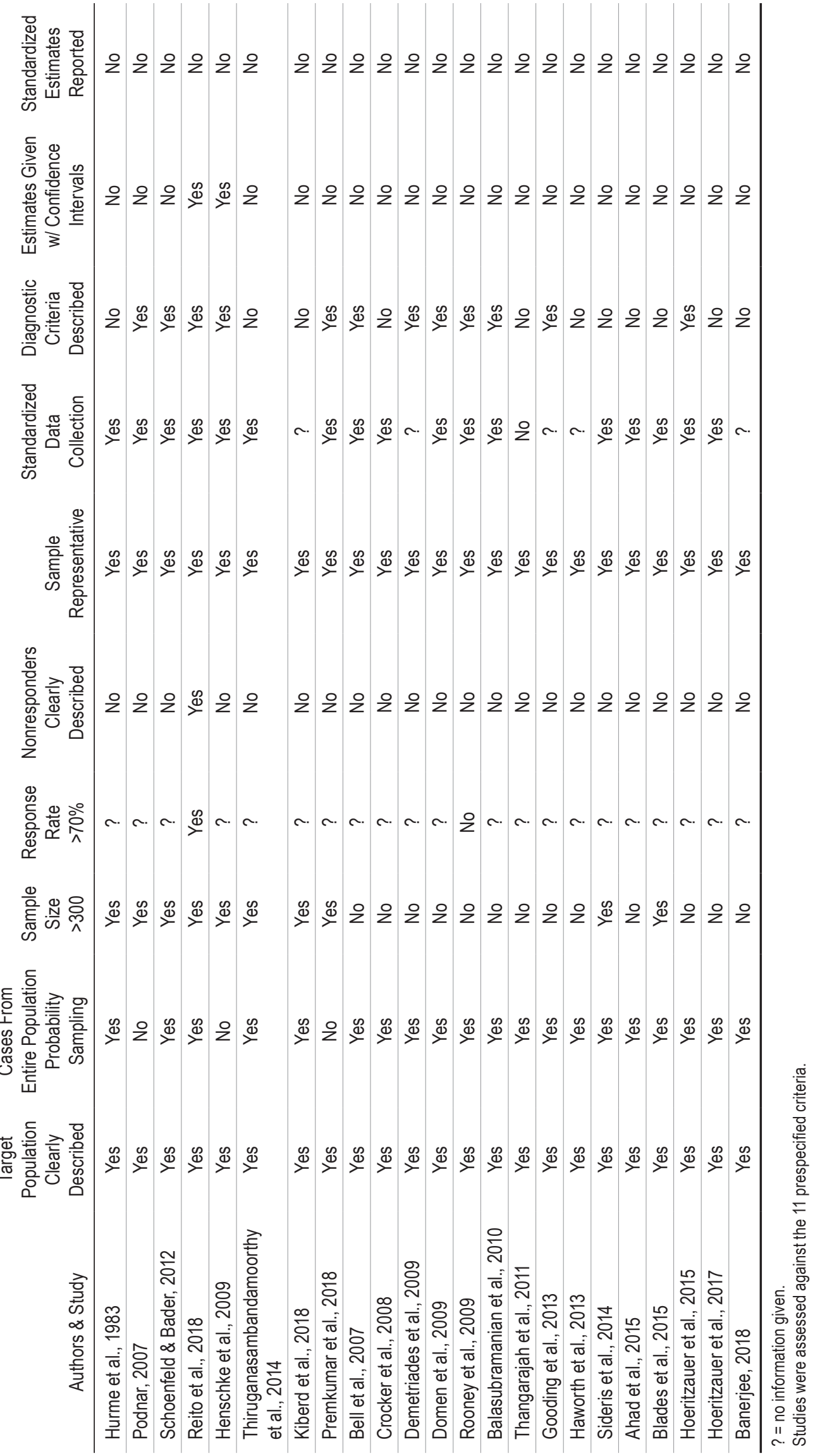


dence of CES could be calculated, but few of the studies had a primary aim to calculate incidence. Many did not meet expected epidemiological standards, as can be seen from Table 4. Sample sizes were small in symptomatic populations and estimates did not have confidence intervals and were not standardized for the populations. Few studies described exclusions or missing data. Nine studies were only published in abstract form and provided fewer methodological details and had not been through the peerreview process. All abstracts and full-text articles were screened by at least 2 reviewers, and we only identified 7 additional studies ${ }^{1,11,15,20,25,47,48}$ through searching reference lists and citations. We are confident that these methods should not have missed any further important studies on this topic.

The criteria used to establish a diagnosis of CES were described in only 13 of the 26 studies, and only 2 studies subdivided CES into clinical categories. ${ }^{40}$ Diagnosis was determined through clinical coding, record review, urgent operative intervention, radiology reports, clinical assessment, or any combination of these. The variation in definitions and reporting of diagnostic criteria likely reflects the lack of agreed definitions and multiple classifications of CES in use clinically and in the literature. ${ }^{18}$ The lack of specific clinical phenotyping covered by a broad CES definition hampers accurate assessment of incidence and contributes to the statistical heterogeneity as the incidence will likely differ depending on the definition and case ascertainment methods used. Adopting agreed-on definitions or defining subtypes such as those listed by Todd and Dickson ${ }^{50}$ might enable more consistent reporting in future studies and allow more accurate incidence figures to be established.

One study was carried out in Australia,23 4 studies were carried out in North America, ${ }^{30,38,43,48}$ and the remaining studies were in European populations. It is not known whether these estimates are relevant outside the populations and healthcare settings studied. Location may determine the availability of imaging and clinical threshold for investigation. All but one ${ }^{15}$ study reporting the proportion of patients with CES from those with suspected CES were carried out in the UK. This may reflect the interest in determining the yield of MRI scanning for suspected CES in a healthcare setting where access to out-of-hours MRI is not always readily available. Guidance from the British Association of Spine Surgeons recommends an emergency MRI for suspected CES, and yet only $14 \%$ of hospitals in England and Wales surveyed in 2012 reported 24-hour access to MRI. ${ }^{21}$ As clinical symptoms and signs in those with radiological cauda equina compression are very difficult to distinguish from those without cauda equina compression, ${ }^{17}$ this leads to a situation in which many patients are transferred to specialist centers for MRI outside office hours and then either transferred back or discharged from locations that can be far from home. In healthcare settings with pressure on MRI services, such as the UK, the threshold for investigating patients with MRI for suspected CES may be higher than in a situation in which MRI is quickly and readily available 24 hours a day. It is not known whether easy access to MRI correlates with a lower diagnostic yield of positive scans for cauda equina compression on MRI due to an increased overall number of patients undergoing MRI.

Healthcare service planning for the investigation and management of CES needs to balance the needs of the majority population with the few CES cases in whom a missed diagnosis or delayed treatment could have significant health and social care consequences for the patient plus medicolegal consequences for the surgeon and healthcare service. Different medicolegal implications in different countries may affect the threshold for investigating and diagnosing CES, which will ultimately affect estimates of incidence. Between 2013 and 2016, there were 131 claims relating to CES in the UK, with a projected value of 68 million. ${ }^{34}$ These were most commonly due to delay in diagnosis or treatment. ${ }^{34}$ In the US, the average payout of 15 lawsuits related to CES between 1983 and 2010 was $\$ 1.57$ million. ${ }^{12}$ It is unknown whether the frequency of legal action for CES in a country is associated with the clinical threshold for investigation of symptoms with an MRI study, as all but one study of patients with suspected CES were carried out in the UK. The high legal costs to the health service of a missed case must be weighed against the costs involved in implementing systems to ensure timely MRI in patients with suspected CES.

Most patients investigated for suspected CES do not have radiological compression on MRI. Although final diagnoses in patients without cauda equina compression include demyelination, myelitis, and infection, a structural cause is not found in the majority of patients. ${ }^{26}$ Further characterization of these patients to identify potentially distinguishing features such as Hoover's sign of functional weakness ${ }^{26}$ could increase the yield of MRI for suspected CES. However, due to the significance of a missed diagnosis, expansion of local out-of-hours MRI provision is more likely to improve care for those investigated for CES with and without structural radiological cauda equina compression. Local MRI services would avoid unnecessary transfer of patients to tertiary services that they do not require.

\section{Conclusions}

CES occurs infrequently in asymptomatic community populations and in only $19 \%$ of those presenting with symptoms. Major limitations in the published literature make it difficult to provide evidence-based services for patients with CES. Multicenter and international studies are required. However, before these can occur, a consensus definition of CES, including clinical and radiological criteria, is needed to allow comparison across centers and throughout the literature.

\section{Acknowledgments}

We thank Sheila Fisken, University of Edinburgh librarian, for her support in designing and developing the search strategy.

\section{Appendix \\ Search Strategies \\ Ovid EMBASE: 1980 to 2018 week 31 \\ 1) Cauda equina syndrome/ \\ 2) cauda equina.ti,ab. \\ 3) Cauda Equina/}


4) 1 OR 2 OR 3

5) Incidence/ OR Prevalence/

6) Epidemiology/

7) incidence* OR prevalen* OR epidemiolog* OR frequenc* OR rate* OR occurrence*).ti,ab

8) 5 OR 6 OR 7

9) 4 And 8

Scopus: July 30, 2018

1) "cauda equina"

2) (incidence* OR prevalen* OR epidemiolog* OR frequenc* OR rate* OR occurrence*)

3) 1 AND 2

\section{References}

1. Ahad A, Elsayed M, Tohid H: The accuracy of clinical symptoms in detecting cauda equina syndrome in patients undergoing acute MRI of the spine. Neuroradiol J 28:438-442, 2015

2. Ahn UM, Ahn NU, Buchowski JM, Garrett ES, Sieber AN, Kostuik JP: Cauda equina syndrome secondary to lumbar disc herniation: a meta-analysis of surgical outcomes. Spine (Phila Pa 1976) 25:1515-1522, 2000

3. Balasubramanian K, Kalsi P, Greenough CG, Kuskoor Seetharam MP: Reliability of clinical assessment in diagnosing cauda equina syndrome. Br J Neurosurg 24:383-386, 2010

4. Banerjee P: Diagnosis of suspected cauda equina syndrome with urgent MRI. The real life scenario. Global Spine J 8 (1 Suppl 1):277S-278S, 2018 (Abstract)

5. Banerjee P, Jalgaonkar A: Back pain with bladder/bowel dysfunction in a child-is this cauda equina syndrome. Global Spine J 8 (1 Suppl 1):262S, 2018 (Abstract)

6. Bell DA, Collie D, Statham PF: Cauda equina syndrome: what is the correlation between clinical assessment and MRI scanning? Br J Neurosurg 21:201-203, 2007

7. Blades D, Heyes G, Robinson K, Eames N: Timing of treatment of cauda equina syndrome at a national treatment centre. Eur Spine J 24:S723, 2015 (Abstract)

8. Boyle MH: Guidelines for evaluating prevalence studies. Evid Based Ment Health 1:37-39, 1998

9. Chau AM, Xu LL, Pelzer NR, Gragnaniello C: Timing of surgical intervention in cauda equina syndrome: a systematic critical review. World Neurosurg 81:640-650, 2014

10. Clopper CJ, Pearson ES: The use of confidence or fiducial limits illustrated in the case of the binomial. Biometrika 26:404-413, 1934

11. Crocker M, Fraser G, Boyd E, Wilson J, Chitnavis BP, Thomas NW: The value of interhospital transfer and emergency MRI for suspected cauda equina syndrome: a 2-year retrospective study. Ann R Coll Surg Engl 90:513-516, 2008

12. Daniels EW, Gordon Z, French K, Ahn UM, Ahn NU: Review of medicolegal cases for cauda equina syndrome: what factors lead to an adverse outcome for the provider? Orthopedics 35:e414-e419, 2012

13. Demetriades AK, Broughton E, Akinwunmi J, Critchley G, Gunasekera L, Norris JS, et al: Out of hours MRI scanning for cauda equina syndrome (CES): what is the positive pickup rate and what are the final diagnoses in those with a negative scan? Br J Neurosurg 23:475, 2009 (Abstract)

14. DerSimonian R, Laird N: Meta-analysis in clinical trials. Control Clin Trials 7:177-188, 1986

15. Domen PM, Hofman PA, van Santbrink H, Weber WEJ: Predictive value of clinical characteristics in patients with suspected cauda equina syndrome. Eur J Neurol 16:416-419, 2009

16. Etemadifar M, Nasr Z, Khalili B, Taherioun M, Vosoughi R: Epidemiology of neuromyelitis optica in the world: a systematic review and meta-analysis. Mult Scler Int 2015:174720, 2015
17. Fairbank J, Hashimoto R, Dailey A, Patel AA, Dettori JR: Does patient history and physical examination predict MRI proven cauda equina syndrome? Evid Based Spine Care J 2:27-33, 2011

18. Fraser S, Roberts L, Murphy E: Cauda equina syndrome: a literature review of its definition and clinical presentation. Arch Phys Med Rehabil 90:1964-1968, 2009

19. Germon T, Ahuja S, Casey AT, Todd NV, Rai A: British Association of Spine Surgeons standards of care for cauda equina syndrome. Spine J 15 (3 Suppl):S2-S4, 2015

20. Gooding BWT, Higgins MA, Calthorpe DAD: Does rectal examination have any value in the clinical diagnosis of cauda equina syndrome? Br J Neurosurg 27:156-159, 2013

21. Hauptfleisch J, Meagher TM, King D, López de Heredia L, Hughes RJ: Out-of-hours MRI provision in the UK and models of service delivery. Clin Radiol 68:e245-e248, 2013

22. Haworth AE, Bhojak M, Wilby M, Das K, Clark S: Out of hours imaging for suspected cauda equina syndrome - a 3 year audit into positive pick up rates in a regional neurosurgical referral centre. Br J Neurosurg 27:281, 2013 (Abstract)

23. Henschke N, Maher CG, Refshauge KM, Herbert RD, Cumming RG, Bleasel J, et al: Prevalence of and screening for serious spinal pathology in patients presenting to primary care settings with acute low back pain. Arthritis Rheum 60:3072-3080, 2009

24. Higgins JPT, Thompson SG: Quantifying heterogeneity in a meta-analysis. Stat Med 21:1539-1558, 2002

25. Hoeritzauer I, Doherty CM, Thomson S, Kee R, Carson A, Eames N, et al: 'Scan-negative' cauda equina syndrome: evidence of functional disorder from a prospective case series. Br J Neurosurg 29:178-180, 2015

26. Hoeritzauer I, Pronin S, Carson A, Statham P, Demetriades AK, Stone J: The clinical features and outcome of scannegative and scan-positive cases in suspected cauda equina syndrome: a retrospective study of 276 patients. J Neurol 265:2916-2926, 2018

27. Hoeritzauer I, Pronin S, Carson A, Statham P, Stone J, Demetriades AK: Investigating the patients who present more than once with cauda equina syndrome symptoms. Spine J 17:S27, 2017

28. Hurme M, Alaranta H, Törmä T, Einola S: Operated lumbar disc herniation: epidemiological aspects. Ann Chir Gynaecol 72:33-36, 1983

29. Hussain MM, Razak AA, Hassan SS, Choudhari KA, Spink GM: Time to implement a national referral pathway for suspected cauda equina syndrome: review and outcome of 250 referrals. Br J Neurosurg 32:264-268, 2018

30. Kiberd J, Hayden J, Magee K, Campbell S: Utility of red flags to identify serious spinal pathology in patients with low back pain: a retrospective analysis. CJEM 20 (Suppl 1):S33-S34, 2018

31. Korse NS, Veldman AB, Peul WC, Vleggeert-Lankamp CLA: The long term outcome of micturition, defecation and sexual function after spinal surgery for cauda equina syndrome. PLoS One 12:e0175987, 2017

32. Kostusiak M, Gnanakumar S, Laing R: Incidence of cauda equina syndrome in patients transferred from district general hospitals to tertiary centre for out of hours MRI. Br J Neurosurg 32:81, 2018 (Abstract)

33. Loney PL, Chambers LW, Bennett KJ, Roberts JG, Stratford PW: Critical appraisal of the health research literature: prevalence or incidence of a health problem. Chronic Dis Can 19:170-176, 1998

34. Machin JT, Hardman J, Harrison W, Briggs TWR, Hutton M: Can spinal surgery in England be saved from litigation: a review of 978 clinical negligence claims against the NHS Eur Spine J 27:2693-2699, 2018

35. Marrie RA, Cohen J, Stuve O, Trojano M, Sørensen PS, Reingold S, et al: A systematic review of the incidence and preva- 
lence of comorbidity in multiple sclerosis: overview. Mult Scler 21:263-281, 2015

36. Moher D, Liberati A, Tetzlaff J, Altman DG: Preferred reporting items for systematic reviews and meta-analyses: the PRISMA statement. PLoS Med 6:e1000097, 2009

37. Podnar S: Epidemiology of cauda equina and conus medullaris lesions. Muscle Nerve 35:529-531, 2007

38. Premkumar A, Godfrey W, Gottschalk MB, Boden SD: Red flags for low back pain are not always really red: a prospective evaluation of the clinical utility of commonly used screening questions for low back pain. J Bone Joint Surg Am 100:368-374, 2018

39. Razak A, Hassan S, Brown D, Hussain M: Who 'owns' suspected cauda equina patients? Br J Neurosurg 31:136, 2017 (Abstract)

40. Reito A, Kyrölä K, Pekkanen L, Paloneva J: Specific spinal pathologies in adult patients with an acute or subacute atraumatic low back pain in the emergency department. Int Orthop 42:2843-2849, 2018

41. Rooney A, Statham PF, Stone J: Cauda equina syndrome with normal MR imaging. J Neurol 256:721-725, 2009

42. Schoenfeld AJ: Incidence and epidemiology of cauda equina syndrome: a review of 976 patients from a complete American population. Spine J 12:100S-101S, 2012

43. Schoenfeld AJ, Bader JO: Cauda equina syndrome: an analysis of incidence rates and risk factors among a closed North American military population. Clin Neurol Neurosurg 114:947-950, 2012

44. Schwarzer G, Carpenter JR, Rucker G: Meta-Analysis With R, ed 1. Berlin: Springer International Publishing, 2015

45. Sideris M, Moore E, Sakthithasan M, Williams AP, Whitfield PC: The evaluation of the clinical presentation, MRI findings and immediate management of potential cauda equina syndrome referrals in a tertiary neurosurgical centre. Int J Surg 12:S54, 2014

46. Srikandarajah N, Boissaud-Cooke MA, Clark S, Wilby MJ: Does early surgical decompression in cauda equina syndrome improve bladder outcome? Spine (Phila Pa 1976) 40:580-583, 2015

47. Thangarajah T, O'Donoghue D, Pillay R: Today or tomorrow? A retrospective analysis of the clinical indications used to request urgent magnetic resonance imaging of the spine. Ann R Coll Surg Engl 93:76-80, 2011
48. Thiruganasambandamoorthy V, Turko E, Ansell D, Vaidyanathan A, Wells GA, Stiell IG: Risk factors for serious underlying pathology in adult emergency department nontraumatic low back pain patients. J Emerg Med 47:1-11, 2014

49. Todd NV: Causes and outcomes of cauda equina syndrome in medico-legal practice: a single neurosurgical experience of 40 consecutive cases. Br J Neurosurg 25:503-508, 2011

50. Todd NV, Dickson RA: Standards of care in cauda equina syndrome. Br J Neurosurg 30:518-522, 2016

\section{Disclosures}

The authors report no conflict of interest concerning the materials or methods used in this study or the findings specified in this paper.

\section{Author Contributions}

Conception and design: Woodfield, Hoeritzauer, Demetriades. Acquisition of data: Woodfield, Hoeritzauer, Wood, Copley. Analysis and interpretation of data: Woodfield, Hoeritzauer, Wood, Copley. Drafting the article: Woodfield, Hoeritzauer, Wood, Copley. Critically revising the article: Woodfield, Hoeritzauer, Demetriades. Reviewed submitted version of manuscript: all authors. Approved the final version of the manuscript on behalf of all authors: Woodfield. Statistical analysis: Woodfield, Wood. Administrative/technical/material support: Hoeritzauer, Wood. Study supervision: Woodfield, Hoeritzauer, Demetriades.

\section{Supplemental Information}

\section{Previous Presentations}

Portions of this paper were presented in poster form at the Society of British Neurological Surgeons, April 11, 2018, Plymouth, United Kingdom.

\section{Correspondence}

Julie Woodfield: Western General Hospital, Edinburgh, United Kingdom.julie.woodfield@ed.ac.uk. 